\title{
PENINGKATAN KESEHATAN JIWA MELALUI PERAN KADER KESEHATAN JIWA
}

\author{
Desak Made Ari Dwi Jayanti ${ }^{1 *}$, Ni Made Nopita Wati ${ }^{2}$, Tri Rahyuning Lestari ${ }^{3}$, Ni \\ Kadek Yuni Lestari ${ }^{4}$, I Gede Juanamasta ${ }^{5}$ \\ Program Studi Keperawatan STIKes Wira Medika Bali
}

Email: $\frac{\text { djdesak@gmail.com }}{1}, \underline{\text { ners.pita@gmail.com }}{ }^{2}, \underline{\text { trilestari100@gmail.com }}^{3}$,

\begin{abstract}
Abstrak
Kegiatan pengabdian bertujuan untuk meningkatkan derajat kesehatan mental dengan meningkatkan peran kader mental untuk memahami Orang dengan Gangguan Mental (ODGJ) dan Orang dengan Masalah Mental (ODMK). Metode yang digunakan (1) ceramah tentang kesehatan mental dan masalah psikososial dan (2) permainan peran tentang cara mempelajari orang-orang dengan penyakit mental dan orang-orang dengan masalah kejiwaan diikuti sesi diskusi tanya jawab. Metode belajar digunakan untuk mentransfer pengetahuan atau keterampilan dan sistem nilai dari pembicara ke kader jiwa. Masalah didominasi kurangnya pengetahuan terkait ODGJ dan ODMK. Bantuan pemecahan masalah yang diberikan adalah memberi pengetahuan, kemampuan, kepada kader jiwa tentang isu-isu ODMK dan ODGJ dan bagaimana melakukan penilaian atau pemindaian
\end{abstract}

Kata kunci: KaderJiwa, ODGJ, ODMK, Scanning

\section{PENDAHULUAN}

Kesehatan jiwa merupakan keadaan dimana individu berkembang menatal, fisik, sosial dan spritual, sehingga individu dapat menyadari kemampuannya, mengatasi tekanan, mampu bekerja secara produktif serta dapat memberikan kontribusi untuk komunitasnya. Koping individu yang tidak dapat berkembang dengan baik dapat menyebabkan gangguan jiwa, yang dapat menyebabkan gangguan pada fungsi jiwa serta menimbulkan derita dan hambatan peran sosial (Keliat, Wiyono and Susanti, 2011).

Orang Dengan Gangguan Jiwa (ODGJ) merupakan orang yang mengalami gangguan dalam pikiran, prilaku, dan perasaan yang terbagi dalam sekumpulan gejala yaitu perubahan prilaku yang bermakna, serta dapat menimbulkan penderitaan dan hambatan dalam menjalankan fungsi orang sebagai manusia. Gangguan jiwa dapat dibagi menjadi 2 yaitu gangguan 
DIFUSI

Volume 2, No.1 Januari 2019

jiwa berat dan gangguan mental emosional. Gangguan jiwa berat ditandai dengan terganggunya kemampuan menilai realitas atau tilikan (insight) yang buruk. Gangguan mental emosional merupakan keadaan yang mengindikasikan individu sedang mengalami perubahan psikologis. Gangguan ini dapat menjadi gangguan yang lebih serius apabila tidak berhasil ditanggulangi (Kementrian Kesehatan, 2013).

Gangguan jiwa dapat disebabkan oleh beberapa faktor yaitu dari faktor badan (somatogenik), lingkungan sosial (sosiogenik), dari psikis (psikogenik), maupun kultural. Gangguan jiwa memiliki beberapa gejala yaitu meliputi gangguan penampilan dan perilaku, gangguan bicara dan bahasa, gangguan proses berpikir, sensorium dan fungsi kognitif, gangguan emosi/perasaan, gangguan persepsi, gangguan psikomotor, gangguan kemauan, gangguan kepribadian, dan gangguan pola hidup. Gejala yang menyertai gangguan ini antara lain berupa halusinasi, ilusi, waham, gangguan proses pikir, kemampuan berpikir, dan perilaku aneh (Maramis and Maramis, 2009).

Tahun 2001, penderita masalah kejiwaan sejumlah 450 juta jiwa dan kemungkinkan meningkat hingga saat ini (World Health Organization and International Council of Nurses, 2007). Riset Kesehatan Dasar Indonesia 2013 menunjukkan 1.728 orang memiliki gangguan jiwa berat, prevalensi menunjukkan 1,7 permil. Peringkat pertama yaitu DI Yogyakarta dan Aceh, peringkat kedua terdapat di Sulawesi
Selatan, peringkat ketiga terdapat di Bali, dan peringkat ke empat terdapat di Jawa Tengah. (Kementrian Kesehatan, 2013).

Riset Kesehatan Dasar Tahun 2013 di Provinsi Bali sebanyak 2,3\% permil jumlah gangguan jiwa berat, sebanyak 143 orang berada Puskesmas II Denpasar Timur. Data Tahun 2015 Dinkes Kota Denpasar menunjukkan dimana 252 orang dari 740.602 jiwa penduduk yang datang berobat ke Puskesmas dengan gangguan jiwa di kota Denpasar (Dinas Kesehatan Kota Denpasar, 2018). Angka tertinggi sebesar $59(41,2 \%)$ ODGJ terdapat di wilayah kerja Puskesmas II Denpasar Timur (Dinas Kesehatan Provinsi Bali, 2018; Puskesmas II Denpasar Timur, 2018a).

Stigma yang berkembang di Indonesia yakni masalah jiwa terjadi karena makhluk jahat, lemah iman, guna-guna dan roh halus yang mengakibatkan pasien mencari pengobatan ke orang pintar yang sering diebut paranormal atau dukun. Hal ini terjadi karena minimnya wawasan dan pengetahuan masyarakat tentang masalah kejiwaan (Keliat, Wiyono and Susanti, 2011). Persepsi keluarga hingga masyarakat yang salah dan minimnya informasi serta pengetahuan berdampak terhadap keterlambatan pengobatan sehingga resiko kekambuhan meningkat. Namun bila keluarga hingga masyarakat memiliki persepsi dan pemahaman yang benar, tindakan yang tepat dan sesuai dapat diberikan pada orang dengan gangguan 
jiwa (Keliat, Wiyono and Susanti, 2011).

Berdasarkan kajian latar belakang maka dibutuhkan strategi untuk mencegah bertambahnya orang dengan gangguan jiwa dimasyarakat. Upaya pencegahan gangguan jiwa terdiri dari pencegahan primer, pencegahan sekunder, dan pencegahan tersier (Keliat, Wiyono and Susanti, 2011). Model Community Mental Health Nursing (CMHN) adalah upaya untuk membantu masyarakat terdampak konflik, bencana, gempa dan tsunami di Aceh sehingga dapat mengatasi masalah-masalah kesehatan mental. Pelaksanaan CMHN dibantu ke tempat yang ruang lingkupnya lebih kecil dengan desa siaga sehat jiwa (DSSJ), masyarakat diarahkan untuk focus bekerja sama dalam menyelesaikan masalah kesehatan mental atau jiwa sehingga masyarakat siap memberikan perawatan ODGJ di rumah (Keliat, Wiyono and Susanti, 2011).

Kader kesehatan jiwa memberikan dampak terhadap proses penemuan kasus baru di masyarakat menjadi lebih mudah dikarenakan masyarakat lebih mudah mendapatkan informasi kesehatan mental atau jiwa. Kader yang dibentuk berperan sebagai sistem pendukung masyarakat khususnya keluarga. Kader wajib melaksanakan deteksi dini kasus ODGJ, penggerakan keluarga untuk ikut penyuluhan kesehatan mental atau jiwa, menggerakan ODGJ dalam rehabilitasi, serta kunjungan rumah (Keliat, Wiyono and Susanti, 2011). Berdasarkan hal tersebut maka kami mengadakan pengabdian masyarakat dengan melakukan pelatihan kader guna meningkatkan pengetahuan dan skill dari para kader.

\section{METODE}

Dalam kegiatan ini metode yang digunakan yaitu:

\section{Pengumpulan data}

Pengumpulan data terkait yang sudah dan akan dilakukan pada kader jiwa di Puskesmas II Denpasar Timur.

2. Wawancara

Berdasarkan hasil wawancara, diketahui didapatkan hasil kurang pengetahuan sebagai kader jiwa.

\section{Pembuatan materi pelatihan}

Penelusuran kajian pustaka terkait kader jiwa yang didapatkan, maka dibuatlah materi yang dibutuhkan dalam pelatihan kader jiwa.

4. Menyajikan materi pelatihan

Penyajian materi dilakukan dengan ceramah dalam bentuk lecture dan dilakukan role play.

\section{HASIL DAN PEMBAHASAN}

Lokasi Abdimas berada di wilayah kerja Puskesmas II Denpasar Timur, berdiri tahun 1992, berlokasi di Jalan Nagasari No. 25 Desa Penatih Dangin Puri. Wilayah kerja Puskesmas merupakan dataran rendah dari tepi pantai Padang Galak sampai berbatasan dengan Desa Jagapati Kabupaten Badung. Luas wilayah kerja Puskesmas $16 \mathrm{Km}^{2}$ terdiri dari Desa Penatih Dangin Puri, Desa Kesiman Petilan, 
DIFUSI

Volume 2, No.1 Januari 2019

Desa Kesiman Kertalangu, Kelurahan Penatih, dan Kelurahan Kesiman, dengan 60 (enam puluh) banjar. Untuk memperluas jangkauan pelayanan, Puskesmas II Denpasar Timur didukung dengan 4 (empat) buah Puskesmas Pembantu yaitu: Puskesmas Pembantu Penatih, Puskesmas Pembantu Kesiman Petilan, Puskesmas Pembantu Kesiman dan Puskesmas Pembantu Kesiman Kertalangu. Jumlah penduduk tahun 2018 adalah 80.544 jiwa dengan lakilaki 41.036 jiwa dan perempuan 39.059 jiwa (Puskesmas II Denpasar Timur, 2018b).

Jumlah orang dengan gangguan jiwa skizofrenia di wilayah kerja Puskesmas II Denpasar Timur bulan Agustus tahun 2018 yaitu sebanyak 113 orang, yang tersebar pada Kelurahan Penatih sebanyak 29 orang, Kelurahan Kesiman sebanyak 17 orang, Desa Penatih Dangin Puri sebanyak 17 orang, Desa Kesiman Petilan sebanyak 23 orang dan di Desa Kesiman Kertalangu sebanyak 27 orang. Program yang sudah dilaksanakan yaitu membentuk kader kesehatan jiwa untuk membantu masyarakat mencapai kesehatan jiwa yang optimal sedangkaan pelaksanaan posyandu jiwa belum secara optimal dilakukan. Melalui wawancara dengan pemegang program mengatakan mengalami kesulitan dalam melaksanakan posyandu jiwa diakibatkan kurangnya tenaga yang dapat melatih kader jiwa sehingga dapat meningkatkan pengetahuan dan keterampilan kader jiwa (Puskesmas II Denpasar Timur, 2018b).

Solusi masalah yang dapat diberikan yaitu memberikan pelatihan kepada kader jiwa tentang apa itu orang dengan gangguan jiwa dan orang dengan masalah kejiwaan, bagaimana melakukan scaning atau pengkajian.. Adapun uraian kegiatan yang telah dilakukan, yaitu:

Tabel 1. Karakteristik Kader Jiwa di Puskesmas II Denpasar Timur Tanggal 25 - 26 Januari 2018

\begin{tabular}{lcc}
\hline \multirow{2}{*}{ Karakteristik } & \multicolumn{2}{c}{ Data Pengabmas } \\
\cline { 2 - 3 } $\mathbf{N}(\mathbf{3 0})$
\end{tabular}

Tabel 1 menunjukkan jenis kelamin sebagian besar kader jiwa adalah perempuan sebanyak 29 orang $(96,67 \%)$, berdasarkan usia terbanyak dengan usia dewasa akhir sejumlah 11 orang $(36,67 \%)$ dan tingkat pendidikan sejumlah $\quad 30$ orang $(100 \%)$ berpendidikan lulus SMA.

Tabel 2. Gambaran pelaksanaan kegiatan kader jiwa hari I, II, dan III

\begin{tabular}{lcc}
\hline \multirow{2}{*}{ Kehadiran } & \multicolumn{2}{c}{ Data Pengabmas } \\
\cline { 2 - 3 } & \multicolumn{2}{c}{$\mathbf{N}(\mathbf{3 0})$} \\
\hline Jumlah Peserta & & $\mathbf{\%}$ \\
Hari I & 30 & 100,0 \\
Hari II & 30 & 100,0 \\
Hari III & 30 & 100,0 \\
\hline
\end{tabular}


DIFUSI

Volume 2, No.1 Januari 2019

Sumber: data primer, 2018

Berdasarkan Tabel 2 menunjukkan kehadiran kader jiwa selama tiga hari dari hari pertama sampai dengan hari ketika $100 \%$ hadir semuanya.

Tabel 3. Gambaran pemahaman peserta

\begin{tabular}{|c|c|c|}
\hline \multirow[t]{2}{*}{ Materi } & \multicolumn{2}{|c|}{$\begin{array}{c}\text { Data Pengabmas } \\
\text { n (30) }\end{array}$} \\
\hline & $\mathbf{f}$ & $\%$ \\
\hline \multicolumn{3}{|l|}{ Kebijakan } \\
\hline \multicolumn{3}{|l|}{ Kesehatan Jiwa } \\
\hline \multicolumn{3}{|l|}{ Masyarakat } \\
\hline Menyimak & 30 & 100,0 \\
\hline Tidak & & \\
\hline Menyimak & 0 & 0 \\
\hline \multicolumn{3}{|l|}{ Optimalisasi } \\
\hline \multicolumn{3}{|l|}{ Layanan } \\
\hline \multicolumn{3}{|l|}{ Kesehatan Jiwa } \\
\hline \multicolumn{3}{|l|}{ Masyarakat } \\
\hline \multicolumn{3}{|l|}{ Melalui } \\
\hline Menyimak & 30 & 100,0 \\
\hline Tidak & & \\
\hline Menyimak & 0 & 0 \\
\hline ODGJ dan & & \\
\hline \multicolumn{3}{|l|}{ ODMK, } \\
\hline \multicolumn{3}{|l|}{ Scaning Awal } \\
\hline Menyimak & 30 & 100,0 \\
\hline \multirow{2}{*}{\multicolumn{3}{|c|}{ Menyimak }} \\
\hline & & \\
\hline Kaji Mantab & & \\
\hline \multicolumn{3}{|l|}{ Kader } \\
\hline \multicolumn{3}{|l|}{ Kesehatan Jiwa } \\
\hline \multicolumn{3}{|l|}{ Pemantauan } \\
\hline \multicolumn{3}{|l|}{ Minum Obat } \\
\hline Menyimak & 30 & 100,0 \\
\hline Tidak & & 0 \\
\hline Menyimak & 0 & \\
\hline
\end{tabular}

Berdasarkan Tabel 3 menunjukkan 30 kader menyimak setiap materi yang diberikan meliputi materi tentang Kebijakan Kesehatan Jiwa Masyarakat, Optimalisasi Layanan Kesehatan Jiwa Masyarakat Melalui posyandu Jiwa, ODGJ dan ODMK, Scaning Awal dan Kaji Mantab Kader Kesehatan Jiwa Pemantauan Minum Obat.

Tabel 4. Gambaran pelaksanaan scanning awal

\begin{tabular}{cccc}
\hline \multirow{2}{*}{ Scaning } & & \multicolumn{2}{c}{ Data Pengabmas } \\
\cline { 2 - 4 } & & f & \% \\
\hline $\begin{array}{l}\text { Jumlah } \\
\text { dilakukan Scaning }\end{array}$ & 30 & 100,0 \\
\hline \multicolumn{3}{c}{ Sumber: data primer, 2018 }
\end{tabular}

Berdasarkan Tabel 4 menunjukkan terdapat $30 \mathrm{KK}$ yang dikunjungi untuk dilakukan scaning awal dan $30 \mathrm{KK}$ tersebut dengan keluarga yang mengalami ODGJ. Jumlah ODGJ yang ada di Wilayah Kerja Puskesmas II Denpasar timur sejumlah 114 orang dan hanya $30 \mathrm{KK}$ yang dikunjungi.

Sebelum dilakukan pelatihan tentang kader jiwa maka peserta diberikan daftar pertanyaan yang digunakan sebagi pre-test pada 30 orang kader jiwa melalui kuesioner.

Tabel 5. Hasil pre-test

\begin{tabular}{ccc}
\hline Pengetahuan & Frekuensi & Presentase \\
\hline Kurang & 11 & 36,67 \\
Cukup & 9 & 30 \\
Baik & 10 & 33,33 \\
Total & 30 & 100 \\
\hline \multicolumn{3}{c}{ Sumber: data primer, 2018 }
\end{tabular}


DIFUSI

Volume 2, No.1 Januari 2019

Hasil pre-test didapatkan mayoritas kader jiwa berpengetahuan kurang sebanyak 11 orang (36,67\%). Pengetahuan adalah hasil penginderaan terhadap suatu objek. Penginderaan manusia, yakni indera pengelihatan, pendengaran, penciuman, rasa dan raba. Mayoritas pengetahuan didapatkan dengan menggunakan mata dan telinga (Notoatmodjo, 2011).

Menurut Notoatmodjo untuk media penyampaian informasi mempengaruhi pengetahuan yang diterima (Notoatmodjo, 2011). Media disusun dengan prinsip setiap pengetahuan diterima oleh panca indra. Kemampuan panca indera yang digunakan untuk menerima sesuatu semakin banyak maka semakin banyak dan jelas pengetahuan yang didapatkan. Media audio visual memberikan informasi melalui suara dan gambar sehingga informasi yang didapatkan oleh penerima dirasakan melalui indera mata dan telinga. Belum ada penelitian atau pengabdian masyarakat yang meneliti tentang pengetahuan kader jiwa sebelum di lakukan pelatihan posyandu jiwa, namun ada beberapa penelitian serupa seperti penelitian yang dilakukan oleh Saleh dan Kunoli dengan judul pengaruh penyuluhan dan pelatihan melalui media leaflet terhadap pengetahuan kader phbs di kecamatan ratolindo kabupaten tojouna-una menunjukkan bawa $50 \%$ responden berpengetahuan rendah (Saleh and Kunoli, 2018). Pengetahuan yang rendah atau kurang terjadi karena kurangnya terpaparnya informasi tentang permasalahan kesehatan jiwa, selain itu bisa juga dipengaruhi oleh pendidikan dimana $100 \%$ kader berpendidikan SMA yang memang selama pendidikan disekolah belum mendapatkan tetang materi bagaimana cara mengenal dan menangani masalah kesehatan jiwa.

Setelah diberikan pelatihan kader menunjukkan terjadi peningkatan dari pengetahuan kader jiwa dimana sejumlah $83,33 \%$ berpengetahuan baik. terjadinya peningkatan tersebut diakatkan karena telah mendapatkan paparan nformasi melalui pelatihan kader.

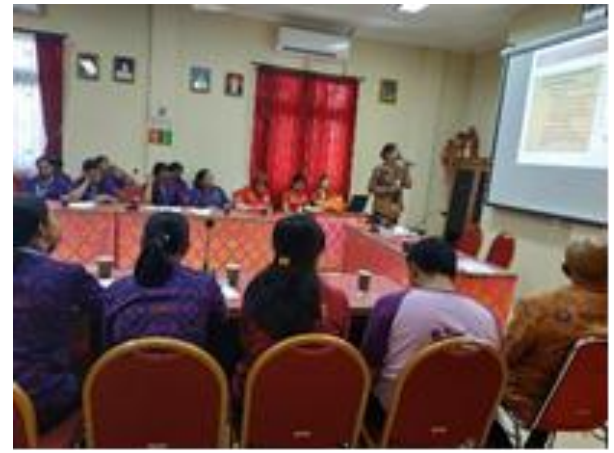

Gambar 1. Kegiatan Pelatihan Kader (Puskesmas II Denpasar Timur, 2018)

Setelah dilakukan pelatihan maka dilakukan post-test melalui kuesioner.

Tabel 6. Hasil pre-test

\begin{tabular}{ccc}
\hline Pengetahuan & Frekuensi & Presentase \\
\hline Kurang & 0 & 0 \\
\hline Cukup & 5 & 16,67 \\
\hline Baik & 25 & 83,33 \\
\hline Total & 30 & 100 \\
\hline \multicolumn{3}{c}{ Sumber: data primer, 2018}
\end{tabular}

Kader memiliki peran promosi dalam layanan kesehatan. Peran promosi kesehatan kader merupakan penghubung antara masyarakat di banjar 
DIFUSI

Volume 2, No.1 Januari 2019

atau RT/RW atau komunitas dengan petugas kesehatan khususnya puskesmas. Kegiatan kader kesehatan diharapkan meningkatkan efektivitas preventif, kuratif dan recovery masalah kesehatan. Kader kesehatan memiliki peran memberikan motivasi dalam minum obat dengan teratur kepada pasien, menjelaskan kepada keluarga dalam memperhatikan dan mengawasi pengobatan pasien, memberikan dukungan kepada keluarga dan pasien dalam mengikuti kegiatan kelompok seperti aktivitas di lingkungan sekitar dan penyuluhan kesehatan serta pasien dihimbau untuk memeriksakan secara teratur di puskesmas (Pramujiwati, Keliat and Wardani, 2013).

Berdasarkan hal tersebut maka kader perlu memiliki pengethuan yang baik. Data ini didukung juga oleh penelitian menurut Saleh dan Kunoli menunjukkan bahwa terjadi peningkatan pengetahuan kader PHBS setelah dilakukan pelatihan dimana yang awalnya dengen pengetahuan baik sejumlah $50 \%$ setelah pelatihan mengalami peningkatan menjadi $75 \%$ dengan pengetahuan baik (Saleh and Kunoli, 2018).

Lukitasari dan Hidayati (2013) menyatakan informasi sangat mempengaruhi pengetahuan seseorang sehingga terjadi perubahan pengetahuan dari dominan pengetahuan kurang saat pre test berubah menjadi dominan memiliki pengetahuan baik setelah diberikan pelatihan. Sumber daya manusia yang berkualitas dapat meningkatkan kualitas hidup dan prognosis penyakit pada ODGJ (Lukitasari and Hidayati, 2013).

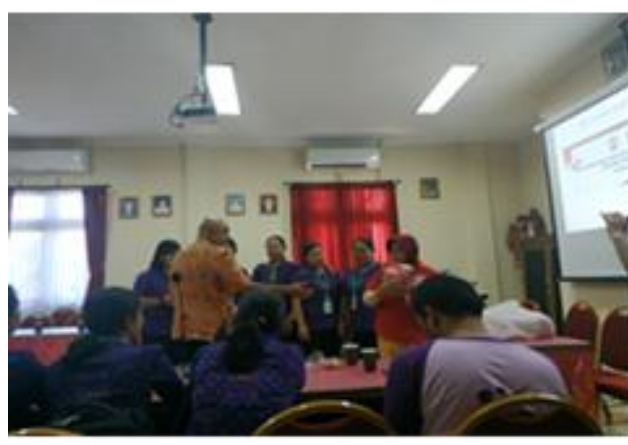

Gambar 2. Kegiatan role play

(Puskesmas II Denpasar Timur, 2018)

\section{KESIMPULAN DAN SARAN}

Simpulan kegiatan ini adalah kegiatan pengabdian kepada masyarakat di wilayah kerja puskemas II Denpasar Timur mendapat sambutan yang baik dan telah berjalan dengan lancar. Program pelatihan kader jiwa memberikan pelatihan dan pengetahuan terkait ODGJ dan ODMK berdampak positif terhadap kinerja kader jiwa dan pelayanan kepada ODGJ dan ODMK.

Saran yang dapat kami berikan yaitu disarankan agar kader jiwa selalu berperan aktif dalam melakukan tugasnya dan diharapkan juga suport dari puskesmas II Denpasar Timur dalam kelanjutan pembentukan posyandu Jiwa.

\section{REFERENSI}

[1] Dinas Kesehatan Kota Denpasar (2018) Laporan Data ODGJ Tahun 2018 Kota Denpasar.

[2] Dinas Kesehatan Provinsi Bali (2018) Laporan Data ODGJ Tahun 2018 Provinsi Bali.

[3] Keliat, B. A., Wiyono, A. P. and Susanti, H. (2011) 'Manajemen 
kasus gangguan jiwa: CMHN (intermediate course)', Jakarta: EGC.

[4] Kementrian Kesehatan, R. I. (2013) Riset kesehatan dasar (Riskesdas) 2013, Jakarta: Badan Penelitian dan Pengembangan Kesehatan.

[5] Lukitasari, P. and Hidayati, E. (2013) Perbedaan Pengetahuan Keluarga Tentang Cara Merawat Pasien Sebelum dan Sesudah Kegiatan Family Gathering Pada Halusinasi Dengan Klien Skizofrenia di Ruang Rawat Inap Rumah Sakit Jiwa Daerah Dr. Amino Gondohutomo Semarang, Jurnal keperawatan jiwa, 1(1).

[6] Maramis, W. F. and Maramis, A. A. (2009) Catatan ilmu kedokteran jiwa. Edisi 2', Surabaya: Pusat Penerbitan dan Percetakan (AUP).

[7] Notoatmodjo, S. (2011) Ilmu Seni Kesehatan masyarakat, Jakarta: Rineka Cipta.
[8] Pramujiwati, D., Keliat, B. A. and Wardani, I. Y. (2013). Pemberdayaan Keluarga Dan Kader Kesehatan Jiwa Dalam Penanganan Pasien Harga Diri Rendah Kronik Dengan Pendekatan Model Precede L. Green Di Rw 06, 07 Dan 10 Tanah Baru Bogor Utara, Jurnal Keperawatan Jiwa, 1(2).

[9] Puskesmas II Denpasar Timur (2018a) Laporan ODGJ.

[10] Puskesmas II Denpasar Timur (2018b) Laporan Tahunan.

[11] Saleh, A. and Kunoli, F. J. (2018) Pengaruh Penyuluhan dan Pelatihan Melalui Media Leaflet Terhadap Pengetahuan Kader PHBS di Kecamatan Ratolindo Kabupaten Tojo Una-Una, PROMOTIF: Jurnal Kesehatan Masyarakat, 8(2), pp. 159-164.

[12] World Health Organization and International Council of Nurses (2007) Atlas: nurses in mental health 2007. World Health Organization. 